\title{
Preditores de saúde em neonatos equinos da raça Campolina
}

Marcela Oliveira ${ }^{[a]}$, Gabriel Faller Almeida ${ }^{[b]}$, Paloma Luany Castello Rabello ${ }^{[a]}$, Andressa Damaceno ${ }^{[a]}$, Gabriela Gaburro

Marangonha ${ }^{[a]}$, Felipe Berbari Neto ${ }^{[a]}$, Graziela Barioni[a] ${ }^{[a}$ Ingrid Bromerschenke ${ }^{[a]}$, Carla Braga Martins ${ }^{[a]}$

[a] Universidade Federal do Espírito Santo (UFES), Alegre, ES, Brasil

[b] Médico veterinário, Cantagalo, ES, Brasil

*Autor correspondente

e-mail: marcela_medvet@hotmail.com

\section{Resumo}

Após o nascimento, o sistema neuroendócrino do neonato precisa se adaptar rapidamente ao ambiente. Em situações de estresse peri e pós-natal, como exemplo, a sepse, hipoxemia e ausência da ingestão de colostro, ocorrem alterações no metabolismo dos carboidratos interferindo nos níveis séricos de glicose e lactato. A hipoglicemia e a hiperglicemia são achados frequentes em casos críticos. 0 lactato sérico tem sido usado como indicador de prognóstico e severidade de doenças em equinos. A determinação da glicemia e lactatemia associada aos parâmetros fisiológicos são importantes para o diagnóstico e tratamento para potros neonatos. Dessa forma, este estudo teve como objetivo avaliar a frequência cardíaca (FC), frequência respiratória (FR), temperatura retal $\mathrm{T}\left({ }^{\circ} \mathrm{C}\right)$ e concentrações séricas de glicose e lactato em potros recémnascidos. 0 protocolo experimental realizado está de acordo com os princípios Éticos da Experimentação Animal, adotados pela Comissão de Ética no Uso de Animais (CEUA), da Universidade Federal do Espírito Santo (Protocolo no 78/2015). Foram utilizados oito potros neonatos da raça Campolina de ambos os sexos, recém-nascidos com até 48 horas de vida, pertencentes a uma propriedade particular situada no município de Cantagalo, estado do Rio de Janeiro. Os animais apresentavam-se hígidos, de acordo com exame clínico realizado antes da colheita de cada amostra. Avaliou-se a frequência cardíaca, frequência respiratória, temperatura retal, coloração das mucosas oral e conjuntival, comportamento e tempo de preenchimento capilar da mucosa oral imediatamente após ao nascimento, 24 e 48 horas após. As amostras de sangue foram obtidas por venopunção da jugular, utilizando-se o sistema de coleta a vácuo imediatamente após o nascimento, 12, 24 e 36 horas após. Para a mensuração da glicemia utilizou-se o glicosímetro portátil Accu-Chek ${ }^{\circledast}$ Active e para a determinação do lactato utilizou-se o lactímetro portátil Active Accutrend ${ }^{\circledast}$ Plus. Os resultados obtidos foram analisados no programa Bioestat ${ }^{\circledR}$, versão 5.3. Para as variáveis fisiológicas 
utilizou-se o teste $\mathrm{t}$ de student. Para a glicemia e lactatemia realizou-se a análise de variância KruskalWallis a nível de $5 \%$ de significância e o teste de Dunn para a comparação das médias. Não houve alteração significativa na $\mathrm{FC}, \mathrm{FR} \mathrm{e} \mathrm{T}\left({ }^{\circ} \mathrm{C}\right)$ nos momentos estudados. A normalidade dos parâmetros fisiológicos evidencia a vitalidade dos recém-nascidos, visto que os potros mamaram colostro até duas horas após o nascimento, tempo considerado normal para a espécie. As placentas não apresentaram alterações macroscópicas dignas de nota e os neonatos não apresentaram alterações comportamentais durante o período experimental. É considerado normal a frequência cardíaca acima de 100 bpm durante a primeira hora de vida devido a adaptação cardiovascular e as tentativas de se levantar. 0 aumento nos demais momentos provavelmente resulta da contenção do animal. A glicemia apresentou aumento significativo nas concentrações 12 horas após o nascimento, mantendo-se constante até 36 horas. Logo após o nascimento, a concentração de glicose sanguínea do potro é baixa. 0 estoque de glicogênio é suficiente para conferir energia por até duas horas após o parto. Após a primeira mamada, os níveis de glicose aumentam significativamente, refletindo a absorção intestinal do colostro, que é altamente calórico. Em relação à lactatemia, notou-se diferença significativa apenas entre o momento 0 e 24 horas, com diminuição significativa nas concentrações de lactato. Os valores elevados após o nascimento podem ser em decorrência do metabolismo anaeróbico promovido pela hipóxia durante o parto. Os potros estudados não apresentaram alterações nos parâmetros clínicos, glicemia e lactatemia indicativas de comprometimento sistêmico no intervalo de 0 a 48 horas pós nascimento.

Palavras-chave: Potro recém-nascido. Bioquímica. Parâmetros clínicos. 